\title{
Practical Approach to Self-Administration of Intravenous C1-INH Concentrate: A Nursing Perspective
}

\author{
C. Symons ${ }^{a} \quad$ O. Rossi ${ }^{b} \quad$ M. Magerl ${ }^{c} \quad$ K. Andritschke ${ }^{d}$
}

${ }^{a}$ Derriford Hospital, Plymouth, UK; ${ }^{b}$ University of Florence, Florence, Italy; ' ${ }^{\mathrm{D}}$ Department of Dermatology and Allergy, Charité - Universitätsmedizin, Berlin, and ${ }^{\mathrm{d}}$ Haemophilia Centre Rhein Main, Mörfelden, Germany

\section{Key Words}

Hereditary angioedema $\cdot$ Self-administration $\cdot$ Practicalities

\begin{abstract}
At an international hereditary angioedema (HAE) expert meeting, results from a survey were used to guide discussion on how best to advise patients on self-administering intravenous $\mathrm{C} 1$ esterase inhibitor therapy. Treatment differences across Europe were highlighted, together with the practicalities of self-administration and useful resources for patients in the future. The international HAE experts noted an increase in the uptake of self-administration, with patients being trained by nursing staff. All patients who are willing and able to self-administer should be offered this treatment option and patients should be encouraged to treat attacks early. Several initiatives were suggested regarding support for patients who self-administer therapy, including a 24hour helpline and home care agencies.
\end{abstract}

Copyright $\odot 2013$ S. Karger AG, Basel

\section{Introduction}

Until recently, it was common practice in most countries that hereditary angioedema (HAE) patients had to present at hospital for the treatment of an attack. However, treatment options for the management of HAE have advanced, with products now licensed for self-administration being offered to patients, for example. Here we discuss practical approaches to self-administration of intravenous $\mathrm{C} 1$ esterase inhibitor $(\mathrm{C} 1-\mathrm{INH})$, with advice gained by consensus at an international HAE expert meeting held in June 2012.

\section{Methods}

To assess the current practice of HAE self-administration treatment across Europe, a survey was sent to a group of experts in the field of HAE (including physicians, nurses and a patient-expert) prior to attendance at an international HAE expert meeting, organised for the purpose of seeking advice on current practice in self-administration treatment of HAE. For further details of the survey, refer to the supplement article by Caballero et al. [1] entitled 'Current status of implementation of self-administration training programmes in various regions of Europe, Canada and the USA in the management of hereditary angioedema'. At the international HAE expert meeting the results of the questionnaire were used to direct discussion. Participants considered how best to advise patients on self-administering intravenous $\mathrm{C} 1$-INH treatment.

\section{Treatment Differences across Europe}

Consensus documents recommend administration of pasteurised-nanofiltered C1-INH for short- (STP) and long-term prophylaxis (LTP) and pasteurised-nanofil-

\section{KARGER}

E-Mail karger@karger.com

www.karger.com/iaa (c) 2013 S. Karger AG, Basel

$1018-2438 / 13 / 1615-0017 \$ 38.00 / 0$
Correspondence to: Sr. Christine Symons

Derriford Hospital, Plymouth Hospitals NHS Trust Derriford Road

Plymouth PL6 8DH (UK)

E-Mail Christine.symons1@nhs.net 
Table 1. Guidelines versus current practice

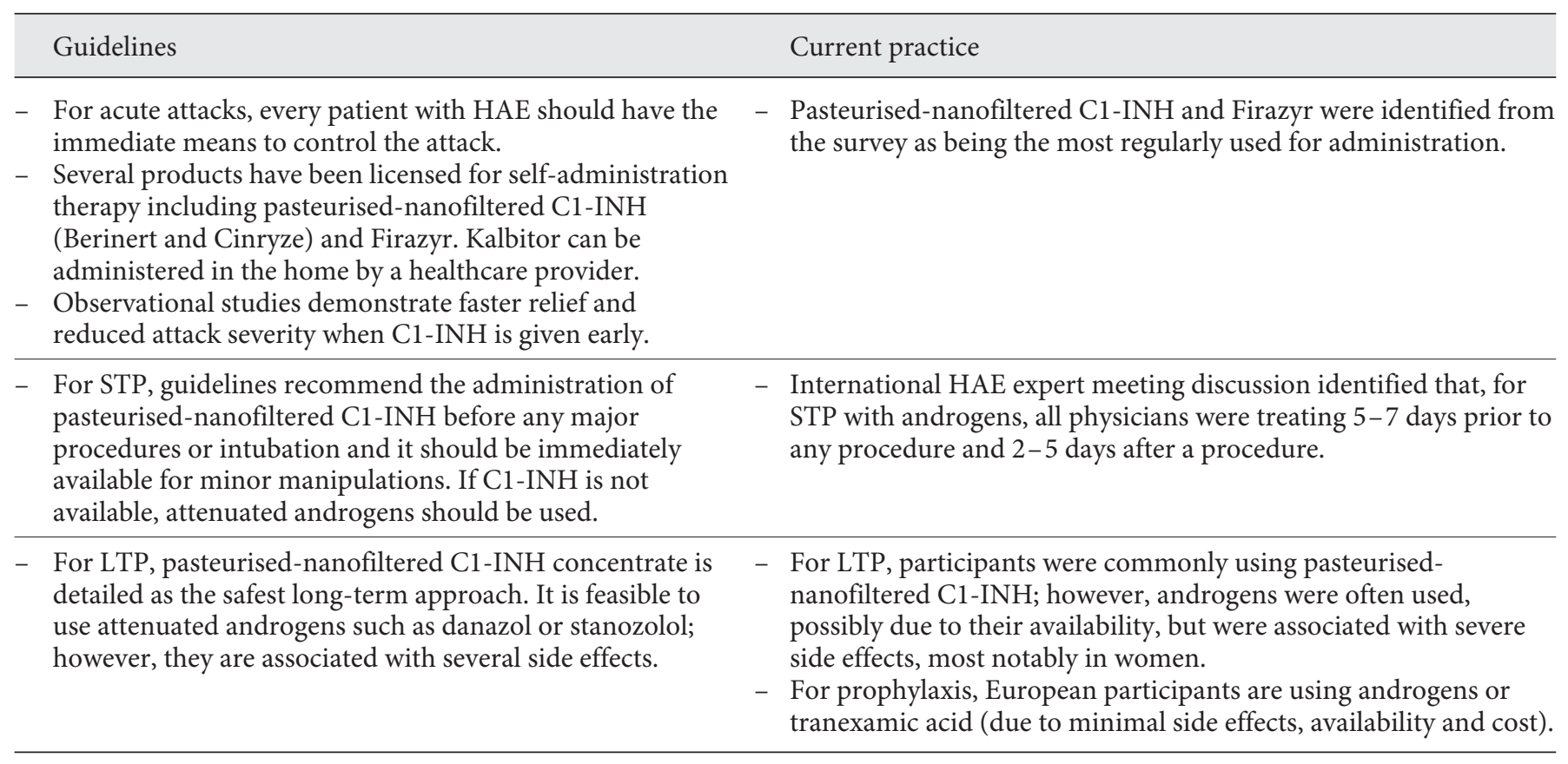

$\mathrm{C} 1$-INH = C1 esterase inhibitor; HAE = hereditary angioedema; LTP = long-term prophylaxis; STP = short-term prophylaxis.

tered C1-INH, icatibant (Firazyr) and ecallantide (Kalbitor) for acute attacks [2]; however, current practice indicates that other products are regularly being used (table 1).

Currently in Spain, France and Germany pasteurised-nanofiltered C1-INH is only approved for use when oral treatment for prophylaxis has failed or on-demand use does not control a patient sufficiently. It was also commented that patient consent is needed in Spain for LTP. In the UK, Italy and Canada, consent is needed to prescribe and document the use of blood products. Although participants used a variety of products, the consensus concluded that the goal of treatment was to treat patients early in an attack. Another factor is cost and reimbursement. In the USA, hospitals charge more for use of a therapy than it costs to purchase but some care packages do not allow self-administration therapy. The economic burden associated with HAE has a significant effect on patients, healthcare systems and society [3]. Analysis of costs by Wilson et al. [4] indicated the largest component of direct cost is hospital stays followed by emergency department visits for acute attacks, whereas the main component of indirect costs varies with attack severity [4]. DOI: $10.1159 / 000351236$

\section{Administration}

The international HAE expert panel identified self-administration as a means to intervene early in acute attacks and give patients control of their own treatment. It was highlighted by the patient-expert that patients prefer the term self-administration over the term home therapy as it removes the connotation of being restricted to the home for administration.

Due to limited experience in Europe, patients are often treated in haemophilia and immunology/allergy centres, where the nursing staff teach administration techniques to HAE healthcare providers. In the UK, there is a wide experience of treating and training patients for self-administration both with hospital staff and home care nurses. In the USA, home care agencies are used to train patients and can follow-up with them in their homes. Participants from centres in Canada and Germany discussed the difficulties with smaller clinics and the need for nurse training programmes.

As noted in guidelines by Longhurst et al. [2], training should be conducted over several sessions to ensure the patient, and any treatment partner, have had sufficient practice to be familiar and confident with the technical 
and medical aspects of self-administration [2]. In practice, a variety of training sessions were offered (table 2).

Overall, the speed at which patients were learning the necessary skill set was surprising, often only taking a few hours. For follow-up training sessions, legislation varies between countries, with some permitting hospital staff access to patients' homes, such as in the UK and Germany, or facilitated by home care agencies in the USA. To improve follow-up in Europe, it was recommended that the use of home care agencies or the addition of a home care option for hospital staff may be worth investing in to help improve patient management. Clinicians were reassured that once the skills have been acquired by a patient they are retained long-term and that frequency of administration alone is not in itself a reason to disregard a self-treatment option.

\section{Practicalities of Administration}

Although consensus documents recommend early treatment of attacks at all sites, this is not thought to be practised (table 3). Patients need to be encouraged not to endure attacks even if they believe they can cope, but to treat them early.

All patients who are willing and capable to do so should be offered self-administration therapy; the skill to selfadminister can be life-saving. The questionnaire circulated prior to the international HAE expert meeting identified that between $50-74 \%$ of physicians' patients are self-administering and that the nursing staff are the main points of contact for training.

International HAE expert consensus agreed that for training purposes, patients are allowed to have with them a 'buddy' who will be able to help with self-administration if required. Initially, patients are taught how to reconstitute the lyophilised product and are talked through the process of intravenous administration and the equipment they need. Patients are then shown how to prepare the equipment and the infusion site, and are shown the technique to infuse. Most patients choose to inject intravenously into their forearm; however, this can sometimes be difficult if the patient is in pain or has hand or eye swelling, which is why the 'trained buddy' may be helpful. To minimise vessel damage, a 25 -gauge butterfly needle is recommended for administration. Patients are also advised that they should keep their preferred vein for self-infusion and they should avoid allowing others to administer intravenous drugs or blood products into their preferred vein.

To aid patients with administration, pharmaceutical companies provide kits that contain a set of components

Self-Administration of C1-INH

Concentrate: A Nursing Perspective
Table 2. Training regimens

\begin{tabular}{|c|c|}
\hline Country & Training regimen \\
\hline Canada & $\begin{array}{l}\text { - Patients are taking approximately } 2-3 \mathrm{~h} \text { to train. } \\
\text { - Shortage of nurses for training. }\end{array}$ \\
\hline Germany & $\begin{array}{l}\text { Several programmes were identified, range } \\
\text { includes: } \\
-3-4 \mathrm{~h} \text { to become proficient (e.g. } 2 \mathrm{~h} \text { on first visit } \\
\text { and } 1-1.5 \mathrm{~h} \text { on second visit). } \\
-3 \text { to } 4 \text { sessions with up to } 2 \mathrm{~h} \text { per session to train } \\
\text { patients. }\end{array}$ \\
\hline Italy & $\begin{array}{l}\text { - Relatively new to self-administration therapy. } \\
\text { - Training programmes managed by physicians and } \\
\text { nurses. }\end{array}$ \\
\hline Spain & $\begin{array}{l}\text { - Relatively new to self-administration therapy. } \\
\text { - Training programmes initiated with help from } \\
\text { haemophilia staff. } \\
\text { - Some centres offer up to } 7 \text { training sessions. }\end{array}$ \\
\hline UK & $\begin{array}{l}\text { - Single training session offered followed by a } \\
\text { refresher course. }\end{array}$ \\
\hline USA & - Home care agencies provide training. \\
\hline
\end{tabular}

Table 3. Attack treatment sites

\begin{tabular}{|c|c|}
\hline Country & Attack site treated \\
\hline Canada & $\begin{array}{l}\text { - Abdominal and laryngeal attacks are always treated. } \\
\text { - Peripheral attacks are treated depending on severity } \\
\text { and frequency; this decision is left to the patient. }\end{array}$ \\
\hline Germany & $\begin{array}{l}\text { - Patients experiencing wandering attacks (i.e. an } \\
\text { attack that starts in the arm and moves to the face) } \\
\text { are encouraged to treat as an attack that can spread } \\
\text { anywhere. }\end{array}$ \\
\hline Italy & $\begin{array}{l}\text { - Patients experiencing wandering attacks (i.e. an } \\
\text { attack that starts in the arm and moves to the face) } \\
\text { are encouraged to treat as an attack that can spread } \\
\text { anywhere. }\end{array}$ \\
\hline Spain & $\begin{array}{l}\text { - Attacks are treated depending on the severity; mild } \\
\text { attacks go untreated. } \\
\text { - Recently, more peripheral attacks are being } \\
\text { treated. Patients can decide if they want to treat. }\end{array}$ \\
\hline UK & $\begin{array}{l}\text { - Patients do not always treat themselves for mild } \\
\text { attacks. } \\
\text { - Participants agreed they need to break the culture } \\
\text { of not treating as they are used to it (able to cope) } \\
\text { and that they should encourage patients to treat all } \\
\text { attacks (as any attack can become severe). }\end{array}$ \\
\hline USA & $\begin{array}{l}\text { - Some patients do not treat mild attacks, but the } \\
\text { consensus suggests they should. }\end{array}$ \\
\hline
\end{tabular}

Int Arch Allergy Immunol 2013;161(suppl 1):17-20 DOI: $10.1159 / 000351236$ 
for dosing. Not all countries require all components because some are supplied in the clinic. Based on feedback from patients, some changes could be made to improve convenience. For example, tubing length could be made longer to aid infusion, or syringes with a larger volume could be used to avoid syringe change; changing the syringe can be challenging for the patient. Patients find the Mix2Vials (Medimop Medical Projects) a very easy system to use, although they are not available in all countries. Other key issues relating to self-administration are discussed in this supplement by Boysen et al. [5] ('Challenges of C1-INH concentrate self-administration').

Intravenous routes of self-administration do not appear to pose a problem for the majority of patients. The international HAE expert meeting members commented that patients like to have the flexibility of intravenous and subcutaneous administration routes as they can select the method appropriate for their setting. For example, people who are travelling find that subcutaneous self-administration is more discreet.

For treatment of children, the participating physicians felt that it was good practice to teach children when they are young as it can help in overcoming any fear of selfadministration. Siblings of the child can assist with teaching them how to self-administer and act as a 'buddy'. In Europe, pasteurised-nanofiltered C1-INH is considered to be a treatment of choice for acute attacks in paediatric patients with HAE as well as for STP and LTP $[2,6]$.

\section{Patient Resources}

In identifying requirements for further training resources, the use of haemophilia and immunoglobulin centres to aid nurse and patient training was recommended. As patients may not have regular contact with a nurse, a 24-hour helpline (as available in haemophilia centres) was also suggested. As patients may forget parts of their training when they are on their own, a check sheet may help to ensure all kit is prepared appropriately and all steps followed in the correct sequence.

\section{Conclusion}

The international HAE experts noted an increased uptake of self-administration, with patients being trained by nursing staff. Nurses have an important role in the training and guidance of patients and as more patients take up self-administration, experience will continue to grow. Where there is minimal experience to date, nurses and patients are attending haemophilia and immunology clinics to learn administration techniques. The experience of haemophilia and immunology nurses needs to be shared across departments, especially within smaller clinics. As patients may not be trained by their regular nurse, a 24hour helpline may be a useful additional resource for patients. So as patients do not feel tied to the home, the term self-administration is preferred over home therapy and we encourage people to use this term when appropriate.

\section{Disclosure Statement}

Sr. Symons has been supported by Shire, ViroPharma and CSL Behring.

Dr. Rossi has received funding from CSL Behring to attend meetings.

Dr. Magerl is, or recently was, a speaker and/or advisor for CSL Behring, Shire/Jerini, Pharming, ViroPharma, Swedish Orphan Biovitrum, Faes Pharma, Uriach and Moxy GmbH.

Ms. Andritschke has participated in advisory boards for CSL Behring.

\section{References}

1 Caballero T, Sala-Cunill A, Cancian M, Craig TJ, Neri S, Keith PK, Boccon-Gibod I, Bethune C, Bork K: Current status of implementation of self-administration training in various regions of Europe, Canada and the USA in the management of hereditary angioedema. Int Arch Allergy Immunol 2013;161 (suppl 1):1016.

-2 Longhurst HJ, Farkas H, Craig T, AygörenPürsün E, Bethune C, Bjorkander J, Bork K, Bouillet L, Boysen H, Bygum A, Caballero T, Cicardi M, Dempster J, Gompels M, Gooi J, Grigoriadou S, Huffer U, Kreuz W, Levi MM,
Long J, Martinez-Saguer I, Raguet M, Reshef A, Bowen T, Zuraw B: HAE international home therapy consensus document. Allergy Asthma Clin Immunol 2010;6:22.

3 HAEi International Patient Organization for C1 Inhibitor Deficiencies: State of management of HAE in Europe. 2011. http://www. haeday.org/sites/default/files/upload/ English\%20PDF-\%20HAEi_Report.pdf (accessed 24 September 2012).

$\checkmark 4$ Wilson DA, Bork K, Shea EP, Rentz AM, Blaustein MB, Pullman WE: Economic costs associated with acute attacks and long-term management of hereditary angioedema. Ann Allergy Asthma Immunol 2010;104:314-320.

5 Boysen HB, Bouillet L, Aygören-Pürsün E: Challenges of $\mathrm{C} 1$-inhibitor concentrate selfadministration. Int Arch Allergy Immunol 2013;161(suppl 1):21-25.

6 Wahn V, Aberer W, Eberl W, Fasshauer M, Kühne T, Kurnik K, Magerl M, Meyer-Olson D, Martinez-Saguer I, Späth P, StaubachRenz P, Kreuz W: Hereditary angioedema (HAE) in children and adolescents - a consensus on therapeutic strategies. Eur J Pediatr 2012;171:1339-1348. 